\title{
What "best practice" could be in Palliative Care: an analysis of statements on practice and ethics expressed by the main Health Organizations
}

\author{
Gaia Barazzetti ${ }^{1,5}$, Claudia Borreani $^{2}$, Guido Miccinesi ${ }^{3 *}$, Franco Toscani ${ }^{4}$
}

\begin{abstract}
Background: In palliative care it would be necessary to refer to a model. Nevertheless it seems that there are no official statements which state and describe that model. We carried out an analysis of the statements on practice and ethics of palliative care expressed by the main health organizations to show which dimensions of end-of-life care are taken into consideration.

Methods: The official documents by the most representative health organisations committed to the definition of policies and guidelines for palliative and end-of-life care had been considered. The documents were analysed through a framework of the components of end-of-life care derived from literature, which was composed of 4 main "areas" and of 12 "sub-areas".
\end{abstract}

Results: Overall, 34 organizations were identified, 7 international organisations, and 27 organisations operating on the national level in four different countries (Australia, Canada, UK and United States). Up to 56 documents were selected and analysed. Most of them (38) are position statements. Relevant quotations from the documents were presented by "areas" and "sub-areas". In general, the "sub-areas" of symptoms control as well as those referring to relational and social issues are more widely covered by the documents than the "sub-areas" related to "preparation" and to "existential condition". Indeed, the consistency of end-of-life choices with the patient's wishes, as well as completion and meaningfulness at the end of life is given only a minor relevance.

Conclusions: An integrated model of the best palliative care practice is generally lacking in the documents. It might be argued that the lack of a fixed and coherent model is due to the relevance of unavoidable context issues in palliative care, such as specific cultural settings, patient-centred variables, and family specificity. The implication is that palliative care staff have continuously to adapt their model of caring to the specific needs and values of each patient, more than applying a fixed, although maybe comprehensive, care model.

\section{Background}

One of the main objectives of a culture is re-orienting death towards life[1]: each person's death threatens society's cohesion by casting a shadow on the feelings of safety and continuity on which every human being bases his/her life and finds support and consolation. For ages the "good death" reflected the community's religious beliefs, and the suffering of the dying person was considered mostly as an unavoidable aspect of the dying process. A good death, in western world, was substantially to die at peace with God and with men[2]. The

* Correspondence: g.miccinesi@ispo.toscana.it

${ }^{3}$ ISPO Institute for the study and prevention of cancer Florence - Italy technological progress of medicine is medicalizing the death more and more, and the gap between the "good" and the actual death has been widening during the last decades[3,4]. Medicine did not deal with dying and death until the birth - some 50 years ago - of the hospice movement, which has the paramount merit of having focused the need of caring for dying persons in order to provide them the best quality of life achievable in their conditions. Actually, the aim of the hospice movement, explicitly or implicitly expressed by its leading persons, is letting terminal patients die better [5,6]. The praxis of palliative medicine, the discipline originated from hospice movement, grounded on scientific approach and rational methods, mainly consists in 
comprehensive treatments of pain and physical symptoms, in caring for the patient's and their family's needs, and in helping them to face anguish and solitude [7].

Palliative interventions are quite effective on physical suffering. Nevertheless, being free from physical symptoms, even if an important aspect of palliative care practice, is not always enough: psychological, social, emotional and spiritual suffering ought to be also controlled [8]. The non-physical suffering, however, is a much more individual and private matter, and refers to the individual's biography, psychology, beliefs, expectations and cultural mind-set $[9,10]$. Treating mental and spiritual anguish with the same approach of body problems does not seem that effective and correct, and for some persons, a good death is sometimes missed [11-13].

It seems that an explicit model of best palliative care practice, accepted by all - at least in western Countries actually does not exist, but the palliative care literature converges towards some specific aspects that contribute to define a death as a good one: symptom control, careful consideration for the social and relational context, preparation to die, and existential wellbeing $[14,15]$. Thus, care must be centred on the patient's wishes and choices [16-18]: palliative care is, in fact, based on autonomy.

A model of best practice in palliative care should be flexible and discussable, and, specially, manifold. It is hardly maintainable that a unique model can be used in a world of moral and cultural strangers [19-21] given that what makes death "good" is different for everyone. In reality, inside hospice movement and palliative care, there are no official statements which state and describe that model. It is, however, probable that the practice of palliative care is actually grounded on a implicit model.

Recently, the category of "good death" as an outcome of palliative medicine has been broadly discussed [7,22-31]. Furthermore the hospice movement has a strong stand against euthanasia and assisted suicide [32-34]. The querelle between palliativists and the rightto-die movement is actually on the limits that ought to be set on the personal autonomy, notwithstanding the common cultural roots of both parties -i.e. "the right of individuals to make their own choices about how they should live and die" [9].

In order to understand if an implicit model of best practice in palliative care does exist, we carried out a qualitative analysis of the statements on practice and ethics of palliative care expressed by the main health organizations to show which dimensions of end-of-life care are taken into consideration.

\section{Methods}

This qualitative study aims at investigating the notion of "best palliative care practice" arising from the official documents by the most representative health organizations committed to the definition of policies and guidelines for palliative and end-of-life care.

The organizations and their documents were selected on the basis of the following three criteria:

- The organization is representative (e.g. on an international or on a national level) of several associations or of professional groups involved in health care.

- The organization has produced documents on ethical, physical and psycho-social issues related to end-oflife care.

- The documents analysed focus on the general practice of palliative care, pain relief and the care of dying patients in general, or deal with more specific end-oflife issues, such as euthanasia, assistance of patients in a permanent vegetative state, sedation at the end of life, and the use of nutrition and hydration, assisted suicide.

The selection and analysis of the documents have been carried out in two phases: a first survey was completed in 2007; this first survey was updated in 2008 in order to find out recently published documents, as well as revisions of the documents included in the first survey.

The procedure adopted for finding the documents combined two methods:

- A retrieval of the directories of organizations available on the websites of the

International Association for Hospice and Palliative Care (IAHPC Directory: http://www.hospicecare.com/ $\mathrm{yp} /$ ) and of the European Association for Palliative

Care (EAPC Directory: http://www.eapcnet.org/organisations/OffBodies\&Ass.html), which allowed to identify several organizations that produced documents.

- A document research on the web (Google search: "position statement" AND ("dying" OR "end of life care" OR "good death" OR "palliative care")), by which it was possible to find out additional documents from a number of organizations that were not included in the directories of the IAHPC and of the EAPC.

The documents were classified as:

a) Documents of palliative care institutions, or other medical or health institutions;

b) Documents on end-of-life/terminality in general, or on a specific situation/need/symptom of end-of-life;

c) Documents classifying themselves as "position statement" (in the title), or "others".

The documents were analysed through a framework of the components of end-of-life care which was developed on the basis of a literature search in a previous work [33]. That review included both qualitative studies on the perceptions of a "good death" amongst patients, caring staff and family members, and more theoretical studies on the origins and the history of the notion of "good death". This thematic grid, which has been 
updated with the most recent citations [11,14,19,30,35-64], was composed of 4 main "areas" (i.e. A, B, C and D) and of 12 "sub-areas" (i.e. A1, A2, etc.) (see table 1).

The content analysis of the documents was carried out with a view to finding out in the texts the various areas and sub-areas of the framework.

\section{Results}

Overall, 34 organizations were identified, i.e. 7 international organizations, and 27 organizations operating on the national level in four different countries (Australia, Canada, UK and United States). Fifty-six documents were selected and analysed.

Additional file 1 provides a list of the documents, including the reference to the name and the level of representativeness (international, or national) of the organization which produced the document, and the code assigned to the document in the course of texts analysis. Moreover, the table indicates the various types of documents selected for this study: most of them (38) are position statements.

Additional file 2 shows all the relevant quotations from the documents analysed. The attachment consists of several tables sorting quotations by "areas" and "subareas", in order to illustrate the specific quotes referring to the elements of the framework.

The presence and the specific meaning of sub-areas in the documents are reported in the following.

\section{A - SYMPTOMS}

\section{A1 - Symptom control}

There is a large convergence of most documents on symptom control, in particular on pain. Pain treatment is as important for doctors and for nurses. The importance of an impeccable early symptom assessment before treating is highlighted. There is a different emphasis on the expected results of symptom control in the documents: some of them refer to "freedom" from pain (e.g. WHO I, EAPC II), whereas others are focussed on "managing" (e.g. WHO II, USA ACS, USA AMA) or "alleviating", "easing" and "mitigating" them (e.g. ICN, ESMO, CANADA CHPCA I, USA NHPCO I). Physical pain is mostly considered as a part of a broader condition of suffering, thus accepting the concept of "total pain" as the specific connotation of the terminal patient.

\section{A2 - Control of anxiety and other psychological symptoms (not dying with fear)}

Psychological suffering is part of the "total pain" and is, as well as the physical symptoms, an objective of the palliative caring. Some of the documents refer specifically to anxiety and depression (i.e. WHO II, CANADA CHPCA I, USA AGS, USA AMA, USA ASCO I, AUSTRALIA ANZSPM I); others describe it as a broader constellation of discomforts associated with impending death (e.g. WMA I, USA AAHPM IV, USA ONS II). These are frequently linked to spiritual or social problems. Some documents, interestingly, consider the psycho-social dimension as a need (e.g. WHO IV, USA ONS II). This perspective implies the search for strategies of need-satisfaction rather than of symptom "sedation".

A3 - Being assisted by a staff in order to make the process of dying more comfortable (both physical and psychological)

In general, accepting the palliative care goal of making the dying process as easy as possible, the documents highlight the role of a multidisciplinary team, with

\section{Table 1 Thematic grid}

\begin{tabular}{|c|c|}
\hline A & SYMPTOMS \\
\hline A1 & Pain and symptom control \\
\hline A2 & Control of anxiety and other psychological symptoms (not dying with fear) \\
\hline A3 & Being assisted by a staff in order to make the process of dying more comfortable \\
\hline B & RELATIONAL AND SOCIAL AREA \\
\hline B1 & Respect of cultural values and individual preferences \\
\hline B2 & Emotional support provided to the family \\
\hline B3 & Good communication among patient/families/close friends/caring staff \\
\hline B4 & Having close people nearby/family acceptance of the patient's condition/not feeling a burden for family and friends \\
\hline C & PREPARATION \\
\hline C1 & Importance given to preparation/awareness of diagnosis/awareness of dying \\
\hline C2 & Choice of place of dying \\
\hline C3 & $\begin{array}{l}\text { Maintaining a sense of control (the possibility of controlling relevant aspects of one's own existence and/or deciding what and when to } \\
\text { delegate to others); maintaining a dimension of continuity of life right to the end }\end{array}$ \\
\hline D & EXISTENTIAL CONDITION \\
\hline D1 & Being at peace with oneself/finding meaning \\
\hline D2 & Spiritual needs/Religious practices \\
\hline
\end{tabular}


special knowledge and skills, in order to deal with the problems and needs of the patients and of their families.

\section{B - RELATIONAL AND SOCIAL AREA}

\section{$B 1$ - Respect of cultural values and individual preferences}

Among the most important elements of caring are the acknowledgement of personal, social, religious and cultural values and beliefs, of both patients and families, as well as the patients' choices about the end-of-life caring. This implies paying special attention to their identification, and respecting and not judging them. One of the documents (i.e. AUSTRALIA PCA II) suggests that also deliberate requests of ending life have to be respected, should they reflect the patient's wishes. Another document (i.e. USA AAFP I) advocates for the availability of instruments that might permit the empowerment of the patients and the respect of their choices.

\section{B2 - Emotional support provided to the family}

This is a common topic in the relational and social area. Family, in fact, is an object of care, together with the patient. Family must be supported also after patient's death. Some documents (e.g. USA AAP, UK NCPC, UK SC, AUSTRALIA AMA) emphasize the importance of a support that should include specific measures such as counselling, in order to help the family to successfully cope with the patient's illness

\section{B3 - Good communication between patient/families/close friends/caring staff}

Communication is a crucial element of care. It must be open, honest, understandable, and must be given in an atmosphere of sensitivity and compassion with adequate emotional support. At the end-of-life, communication concerns the symptoms, their cause and treatment options, as well as issues related to death and dying. Some documents (e.g. USA ASCO II) claim for a health professionals' specific training. One of the documents points out that nurses should advocate for the communication of the patient's preferences across the various health-care settings (i.e. CANADA CNA).

\section{B4 - Having close people nearby/Family acceptance of the patient's condition/Not feeling a burden for family and friends}

Family is acknowledged as a crucial element of end-oflife care, but this care must not become an unbearable burden. The care must be freely and consciously accepted and carried out by the relatives. The appropriate climate for a dying person ought comprehend the following elements: physical and emotional closeness; acceptance of death; providing the patient does not feel her/himself as a burden for the caregivers.

\section{C - PREPARATION}

\section{C1 - Importance of preparation/awareness of diagnosis/} awareness of prognosis (awareness of dying)

The analysis of the documents has shown that the awareness of diagnosis and prognosis (and of impending death) is not considered as relevant. Amongst the international organizations, only one (i.e. WHO I) acknowledges the importance of preparation. In the documents that take this into account, the term "preparation" does not exclusively refer to death, but more often to the dying process. In general, these documents recommend paying a thoughtful attention to the patient's verbal and non-verbal communication in order to understand when and if that very patient is ready to deal with these subjects; and to let the patient feel that the caregiver too is ready to give her/him every explanation and answer.

\section{C2 - Choice of place of dying}

Among the few documents that consider this issue, five (i.e. WHO IV, CANADA CHPCA I and II, USA AAHPM IV, and USA AGS) refer to the setting of care in the last phases of life, and four documents (i.e. CANADA CNA, USA AAP, USA AMA, AUSTRALIA CARNA) refer to the place of death. No specific setting is considered as the most suitable a priori, whether it is the place where the final days of life have to be spent, or the place where death will occur: the place ought be chosen on the patient's preference and/or needs.

C3 - Maintaining a sense of control (possibility of controlling relevant aspects of one's own existence and/or deciding what and when to delegate to others)/Keeping a dimension of continuity of life right to the end

The relevance given to the patient's empowerment is very high. It is important that the patient is helped to keep the control on the dying process by means of: an adequate and effective support; the share of the decision-making; the exploitation of her/his resources; the respect of her/his freedom of choice; advanced directives.

\section{D - Existential condition}

\section{D1 - Being at peace with oneself/finding meanings}

Only a few documents take this issue into account. For those nearing the end of life, impending death could be an opportunity to give meaning to the disease and/or to their life. Thus, the caregivers have to help the patient to this task.

\section{D2 - Religious or spiritual practices}

The assessment of spiritual and religious needs is considered as a relevant element of a good end-of-life care. The caregivers are committed to acknowledge the spiritual needs and to facilitate the accomplishment of specific religious practices. One of the documents (i.e. USA HPNA III), focusing on spiritual care at the end of life, emphasizes the importance of acknowledging and supporting patient's spiritual beliefs and expressions, and recognizes the patient's right to decline religious support.

The analysis of the documents led to the identification of additional key-elements of end-of-life care that were not included in the framework taken from the review of literature. 
A description of the additional areas and sub-areas arising from the statements is provided in the following.

\section{E - End-of-life decisions}

\section{E1 - Death as natural or normal/Not to hasten nor to} postpone death

Overall, 11 documents consider death as a "normal" process and "a natural part of life progression", and 9 documents explicitly refuse any kind of medical intervention directed to "hasten" or to "postpone" death. In 5 documents the rationale behind the refusal of interventions that deliberately hasten death is that dying has to be considered as a normal part of the life process. There is a nuanced difference between the documents stating that palliative care should not accelerate nor delay death (e.g. WHO I, EAPC I, UK SC), and documents affirming that palliative care does not intend to accelerate nor postpone death (e.g. USA HPNA I, USA ONS I). Interestingly, one document contends that the naturalness of death is compatible with declining or withdrawing futile treatments (i.e. AUSTRALIA PCA II). Two of the documents refer to the rule of "double effect" to justify the use of pain medication which might have a secondary and unintended effect of hastening death (i.e. CANADA CNA, USA HPNA I).

\section{E2 - Death as an unwanted effect of sedation/Withdrawing or withholding treatments/Euthanasia and assisted suicide}

Euthanasia and assisted suicide are considered unethical, but terminal pharmacological deep sedation and the (even if rare) life shortening due to effective/high doses of analgesics and/or sedatives are not to be considered as euthanasia (e.g. USA AAHPM V, USA HPNA I). In general, the withdrawing or the withholding of treatments are considered as acceptable measures only if treatments do not effect any amelioration of the patient's condition, but merely prolong the process of dying (e.g. WHO I, EAPC II, USA AMA). One of the documents (e.g. USA ACS) highlights the doctor's responsibility of sparing futile treatments in every situation that involves imminent dying. Nevertheless, several documents clearly state that withdrawing and withholding treatments (including life-sustaining measures) should be consistent with the patient's wishes (e.g. WMA III, CANADA CHPCA II, USA AAHPM II). Amongst these documents, one clearly states that artificial nutrition and hydration should be considered as any other treatments and might be withhold or withdrawn when doing so is consistent with the patient's preferences (i.e. USA NHPCO IV).

\section{E3 - Participation in the decision-making process}

All documents maintain that patients should be involved in every decision concerning treatments. Up to 12 documents by international and national organizations (e.g. WMA I, USA HPNA I, USA NHPCO IV, CANADA CHPCA I, AUSTRALIA AMA) clearly state that patients have a "right" to make informed decisions on treatments, including the right to refuse treatments. Five of the documents (i.e. CANADA CHPCA II, CANADA CNA, USA AAHPM II, USA AMA, USA NHPCO IV) provide indications on advanced directives, formal living will, the designation of proxy decision-makers, which are considered as a means to collect and honour the patient's choices. Interestingly, one of the documents (e. g. EAPC II) supports a more nuanced participation of the patient in the decision-making process, thus referring to a specific time in the disease progression, when it is right to honour the patient's refusal of treatment that prolong suffering without any gain for the patient's condition.

\section{F - Quality of life}

A considerable number of documents consider quality of life as the main goal of care at the end of life. This goal is so important that is licit to forgo any other result, including prolonging life or keeping the patient alive. Most of these documents assume that quality of life is a relevant parameter of an effective palliative care. In particular, three of the documents maintain that quality of life should be defined by each patient (i.e. CANADA CHPCA II) and by his/her family (i.e. CANADA CHPCA I, AUSTRALIA CARNA). Only one document (i.e. WHO I) acknowledges the need of instruments to measure the quality of remaining life, and provides a list of items that should be evaluated in order to establish it. All the other documents do not provide a description of how to assess the quality of life of patients facing impending death. Some documents (i. e. WHO I, WHO V, CANADA CHPCA I, UK NCPC) explicitly refer to the quality of life of family members taking care of patients who suffer a life-threatening illness. One of the documents details specific therapies that might improve the patient's quality of life (i.e. USA AAP).

\section{G - Dignity}

A few documents refer to the issue of dignity, although the meaning of this term is altogether nuanced and variable. Some documents (i.e. ICN, CANADA CHPCA I, USA ANA) refer to a "dignified death", while others allude to a general "sense of dignity" (i.e. CANADA CHPCA II) or to the possibility of maintaining "dignity and independence" (i.e. USA AGS) as something that should be guaranteed to dying patients. One of the documents affirms that the caring staff should approach death in a way that it "dignifies life" (i.e. UK SC). In general, a specific definition of the term "dignity" is lacking.

\section{Discussion}

Analysis of the documents shows that all the dimensions of end-of-life care found in the literature and included 
in the framework (see Table 1: Thematic grid) are echoed in the statements of the most representative organizations committed to the definition of policies and guidelines for palliative and end-of-life care. It is worth noting that all the national organizations found according to our research strategy belong to English speaking countries. This might be due to the fact that it was in these countries that the palliative care movement first developed and flourished in the $60 \mathrm{~s}$ and $70 \mathrm{~s}$.

In general, the "sub-areas" of symptom control (i.e. $\mathrm{A} 1, \mathrm{~A} 2$ and $\mathrm{A} 3$ ) as well as those referring to relational and social issues (i.e. B1, B2, B3 and B4) are more widely covered by the documents than the "sub-areas" related to "preparation" (i.e. C1, C2 and C3) and to "existential condition" (i.e. D1 and D2). This result is consistent with what is stated by several studies showing that the control of symptoms and of the psychosocial dimension of dying $[15,17,25,26,35-41]$, is given a higher relevance than the control of the dying process by the patient himself $[15,19,25,26,34,51,55]$.

With regard to symptoms, the control of pain and of psychological distress (i.e. A1 and A2) is acknowledged as fundamental, while being assisted by a staff member in order to make the process of dying more comfortable (i.e. A3) is considered as less relevant. This result seems to be counteracted by the evidence from the literature, which shows that being comfortable is seen as important both by patients and by health care professionals [59].

As to the relational and social dimension, a large number of documents state that individual preferences as well as personal values and beliefs (i.e. B1) should be respected and honoured. This issue has been extensively discussed in the literature $[4,12,23,25,51,56,60]$ and is particularly relevant for patients sharing cultural values which are different from those dominant in society [17].

Most documents combine the respect for personal beliefs and values with the importance of addressing one's spiritual needs and of facilitating religious practices (i.e. D2), thus showing consideration for individual preferences both from the relational and from the existential perspective. However, the importance attributed to respect for individual preferences seems to be in contradiction with the minor weight lent to the choice of the place of dying (i.e. C2).

Further discrepancies can be found between issues related to preparation and issues related to the relational and social dimension of dying. Indeed, many documents recognise the importance of good communication between the patient and the caring staff (i.e. B3), and state that communication should include information about diagnosis and prognosis, as well as the discussion of issues related to death and dying. Yet, this result jars with the fact that only a few documents refer to the awareness of diagnosis and of impending death (i.e. C1), an omission which is even more striking since how often Western surveys address this issue $[4,12,23,25,51,53,57,60]$.

It might be argued that, due to the discrepancies between the element of preparation and the relational and social area, it is not possible to derive from the documents an integrated model of best palliative care practice. In particular, it might be suggested that the documents do not offer a coherent model for policies directed to the actual empowerment of patients in the decision-making process. This is especially evident with regard to end-of-life decisions. While there is a general agreement between the documents that patients should take part in end-of-life choices, withdrawing and withholding of life-sustaining treatments are viewed as the result of an evaluation that is mainly up to the doctor. Indeed, the consistency of end-of-life choices with the patient's wishes is given only a minor relevance.

Another result that is worth discussing is the small relevance given to being in control of oneself (i.e. C3). Only one third of the documents refers to this item, whereas it is one of the most important elements of end-of-life care present in the literature [59]. This might be due to the fact that the maintenance of control is a multifaceted and a patient centred issue, which can only with difficulty be addressed by policy statements on palliative and end-of-life care. The same conclusion may be suggested for completion and meaningfulness at the end of life (i.e. D1), which is given a minor relevance in the documents, while several qualitative studies on patients, families and caregivers account for this item $[12,17,23,56,60,62]$.

On the other hand, there seems to be no persuasive explanation to the fact that minimising the burden of caring on the family is hardly covered in the statements. While, according to the literature, freedom from financial and physical burden is considered by patients and caregivers as one of the most important component of a end-of-life care $[17,56,58,59,61]$ only a few documents address this issue. It might be suggested that, in general, the statements tend to consider "financial and physical" support to the family as less relevant than "emotional" support. In fact, a great number of documents consider emotional support to the family (i.e. B2) as reasonably important. Nevertheless, this consideration does not prevent from observing that minimizing the burden of care is generally underestimated in the documents.

Finally, it is worth noting that a definition of quality of life at the end of life is lacking, whereas this issue is widely covered by the documents. Of course, the concept of quality of life is highly individual and fluid, and it might be difficult to give a precise definition of this notion. However, several studies have already proved the 
possibility of developing instruments to assess both the quality of life for dying patients and the quality of care at the end of life $[52,57,59,63,64]$. Therefore, it might be observed that the documents generally fail to address the issue of quality of life in a consistent and precise manner.

\section{Conclusions}

This work demonstrates that all the dimensions of endof-life care stemming from the literature are reflected in the official documents by the most representative organizations committed to the definition of guidelines for the care of the dying patients. A few additional items emerged from the analysis of the documents, thus completing the framework which was formerly taken from the literature. The resulting grid (see Table 2: New thematic grid) consists of a more comprehensive framework, which might facilitate the assessment of the high quality palliative care process.

On the other hand, an integrated model of best palliative care practice is generally lacking in the documents. It might be argued that the lack of a fixed and coherent model is due to the relevance of unavoidable context issues in palliative care, such as specific cultural settings, patient-centred variables, and family specificity. The implication is that palliative care staff have continuously to adapt their model of caring to the specific needs and values of each patient, more than applying a fixed, although maybe comprehensive, care model.

Additional file 1: list of documents. list of documents with name and
level of representativeness of the organizations, and code assigned for
the text analysis.
Click here for file
[http://www.biomedcentral.com/content/supplementary/1472-684X-9-1-
S1.DOC]
Additional file 2: quotations. quotations from selected documents
sorted by areas and subareas.
Click here for file
[http://www.biomedcentral.com/content/supplementary/1472-684X-9-1-
S2.DOC ]

\section{Acknowledgements}

\section{Funding}

The study was supported by the Istituto di Ricerca in Medicina Palliativa "Lino Maestroni"- ONLUS - Cremona (Italy). The first Author received a specific funding in order to perform the search and the analysis of the documents. The Istituto di Ricerca in Medicina Palliativa "Lino Maestroni" made the payment for the online publication too. The Istituto di Ricerca in Medicina Palliativa "Lino Maestroni" did not interfere in any way in the collection, analysis and interpretation of data, neither in the writing of the manuscript or in the decision to submit the manuscript for publication

\section{Author details}

'Department of Philosophy University "Vita-Salute San Raffaele" Milan - Italy. ${ }^{2}$ Psychology Unit National Cancer Institute Milan - Italy. ${ }^{3}$ ISPO Institute for the study and prevention of cancer Florence - Italy. ${ }^{4}$ Scientific Director Research Institute for palliative medicine "Lino Maestroni" Cremona - Italy. ${ }^{5}$ Current Address: University of Lausanne, EPFL College of Humanities, Switzerland.

Table 2 New thematic grid

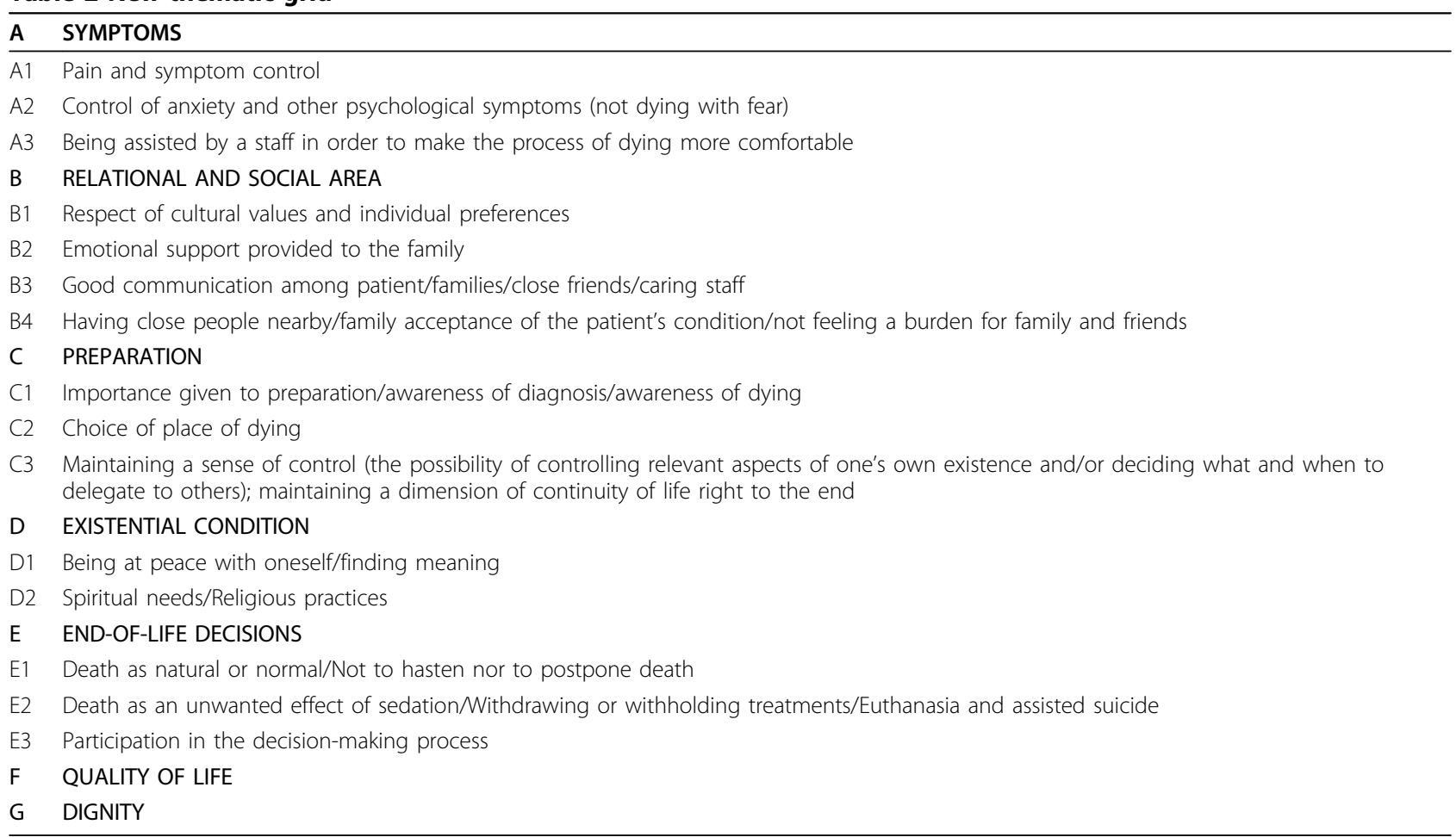




\section{Authors' contributions}

GB performed the search and analysis of the documents. CB and GM participated in the analysis and wrote the different versions of the paper. FT discussed the results and wrote the background section. All authors read and approved the final manuscript.

\section{Competing interests}

The authors declare that they have no competing interests.

Received: 9 March 2009

Accepted: 7 January 2010 Published: 7 January 2010

\section{References}

1. Seale C: Constructing death. The sociology of dying and bereavement. Cambridge: Cambridge University Press 1998.

2. Ariès P: Western attitudes towards death. Baltimore, M.D.: Hopkins University Press 1974.

3. Clark D: Between hope and acceptance: the medicalisation of dying. $B M$ 2002, 324(7342):905-7.

4. Smith R: A good death. BMJ 2000, 320:129-130.

5. Byock IR, Forman WB, Appleton M: Academy of Hospice Physicians's Position Statement on Access to Hospice and Palliative Care. Journal of Pain and Symptom Management 1996, 11(2):69-70.

6. Doyle D, Hanks GWC, MacDonald N: Introduction. Oxford Textbook of Palliative Medicine Oxford, New York, Tokyo: Oxford University PressDoyle D, Hanks GWC, MacDonald N , 2 1998, 3-8.

7. Storey P: Goals of hospice care. Tex Med 1990, 86(2):50-4.

8. Ellershaw J, Ward C: Care of the dying patient: the last hours or days of life. BMJ 2003, 326(7379):30-4.

9. Walter T: Historical and social variants on the good death. BMJ 2003, 327:219.

10. DelVecchio Good MJ, Gadmer NM, Ruopp P, Lakoma M, Sullivan AM, Redinbaugh E: Narrativenuances on good and bad deaths: internists' tales from high-technology work places. Soc Sci Med 2004, 58(5):939-53.

11. Saunders C: Spiritual pain. J Palliat Care 1988, 4(3):29-32.

12. Low JT, Payne S: The good and bad perceptions of health professionals working in palliative care. Eur J Cancer Care 1996, 5:237-241.

13. Payne SA, Hillier R, Langley-Evans A, Roberts T: Impact of witnessing death on hospice patients. Soc Sci Med 1996, 43(12):1785-1794.

14. Turner K, Chyle R: Dignity in dying: a preliminary study of patients in the last three days of life. Journal of Palliative Care 1996, 12:7-13.

15. Singer PA, Martin DK, Kelner M: Quality end-of-life care: patients' perspectives. JAMA 1999, 2(2):163-8.

16. Clark J: Patient centered death. BMJ 2003, 327:174

17. Tong E, McGraw SA, Dobihal E, Baggish R, Cherlin E, Bradley EH: What is a good death? Minority and non-minority perspectives. J Palliat Care 2003, 19(3):168-75.

18. Hanson LC, Tulsky JA, Danis M: Can clinical interventions change care at the end of life?. Ann Intern Med 1997, 126(5):381-8.

19. Payne SA, Langley-Evans A, Hillier R: Perceptions of a "Good" death: a comparative study of the views of hospice staff and patients. Palliative Medicine 1996, 10:307-312.

20. Hermsen MA, ten Have HA: Euthanasia in palliative care journals. J Pain Symptom Manage 2002, 23(6):517-25.

21. Lynn $J$, et al: Is there a place for active euthanasia in palliative care. $J$ Palliat Care 1988, 4(1 and 2):99-121.

22. Materstvedt LJ, Clark D, Ellershaw J, Forde R, Gravgaard AM, MullerBusch HC: Euthanasia and physician-assisted suicide: a view from an EAPC Ethics Task Force. Palliat Med 2003, 17(2):97-101, discussion 102-79.

23. Mak JM, Clinton M: Promoting a good death: an agenda for outcomes research-a review of the literature. Nurs Ethics 1999, 6(2):97-106.

24. Powis J, Etchells E, Martin DK, MacRae SK, Singer PA: Can a "good death" be made better? A preliminary evaluation of a patient-centred quality improvement strategy for severely ill in-patients. BMC Palliat Care 2004, $3(1): 2$

25. Schwartz CE, Mazor K, Rogers J, Ma Y, Reed G: Validation of a new measure of concept of a good death. J Palliat Med 2003, 6(4):575-84

26. Steinhauser KE, Christakis NA, Clipp EC, McNeilly M, McIntyre L, Tulsky JA: Factors considered important at the end of life by patients, family, physicians, and other care providers. JAMA 2000, 284(19):2476-82.
27. Cohen LM, Poppel DM, Cohn GM, Reiter GS: A very good death: measuring quality of dying in endstage renal disease. J Palliat Med 2001, 4(2):167-72.

28. Sullivan MD: The illusion of patient choice in end-of-life decisions. Am J Geriatr Psychiatry 2002, 10(4):365-72.

29. Thompson T, Barbour R, Schwartz L: Adherence to advance directives in critical care decision making: vignette study. BMJ 2003, 327:1011-1017.

30. Low JT, Payne S: The good and bad death perceptions of health professionals working in palliative care. Eur J Cancer Care 1996, 5(4):237-41.

31. McNamara B, Waddell C, Colvin M: The institutionalization of the good death. Soc Sci Med 1994, 39(11):1501-8.

32. Engelhardt HT Jr: The Principles of Bioethics. Oxford: Oxford University press 1986.

33. Toscani F, Boeri P, Borreani C, Miccinesi G: Life at the end of life: beliefs about individual life after death and "good death" models - a qualitative study. Health Qual Life Outcomes 2003, 1(1):65.

34. Jones J, Willis D: In search of a good death: What is a good death?. BMJ 2003, 327(7408):224

35. Seale CF, Addington-Hall JM, McCarthy M: Awareness of dying: prevalence, cause and consequences. Social Science \& Medicine 1997, 45:477-484.

36. Speck P: Spiritual issues in palliative care. Oxford Textbook of palliative medicine Oxford, New York, Tokyo: Oxford Med PublDoyle D, Hanks GWC, MacDonald N , II 1998, 810-814.

37. Keizer M, Kozak F, Scott J: Primary care providers' perceptions of care. Journal of Palliative Care 1992, 4(8):8-12.

38. Miller FG: The good death, virtue and physician-assisted death: an examination of the hospice way of death. Cambridge Quarterly of Healthcare Ethics 1995, 4:92-97.

39. Wallston K, Burger C, Smith RA, Baugher RJ: Comparing the quality of death for hospice and non hospice cancer patients. Medical Care 1988, 26(2):177-182.

40. McNeil C: A Good Death. Journal of Palliative Care 1998, 14(1):5-6.

41. Vovelle M: La Mort et I'Occident de 1300 à nos Jours. Paris: Gallimard 1983.

42. Mc Namara B, Waddell C, Colvin M: The institutionalization of the good death. Soc Sci Med 1994, 39(11):1501-1508.

43. Callahan D: Pursuing a peaceful death. Hasting Center Report 1993.

44. Bertman SL: Facing death: images, insights and interventions. Washington D.C: Hemisphere Publishing Corporation 1991.

45. Gilmore A, Gilmore S: A Safer Death. New York: Plenum Press 1987.

46. Hart B, Sainsbury P, Short S: Whose dying? A sociological critique of the "good death. Mortality 1998, 3(1):65-77.

47. Jomain CH: Mourir dans la tendresse. Paris: Le Centurion 1986

48. Baudry P: La mort provoque la culture. Mortality La mort et moi et nous Paris: Le Penser-Vivre TextuelAugé M 1995.

49. Brown M: A good death. Principles of palliative care are yet to be applied in acute hospital?. BMJ 2000, 320(7243):1206.

50. Thobaben M: Helping terminally ill clients experience a "good death. Home Care Provid 2000, 5(6):202-203.

51. Pierson CM, Curtis JR, Patrick DL: A good death: a qualitative study of patients with advanced AIDS. AIDS Care 2002, 14:587-592.

52. Vig EK, Pearlman RA: Quality of life while dying: a qualitative study of terminally ill older men. J Am Geriatr Soc 2003, 51:1595-1601.

53. Vig EK, Pearlman RA: Good and bad dying from the perspective of terminally ill man. Arch Intern Med 2004, 164:977-981.

54. Teno JM, Casey VA, Welch LC, Edgman-Levitan S: Patient-focused, familycentered end-of-life medical care: views of the gudelines and bereaved family members. J Pain Symptom Manage 2001, 22:738-751.

55. Steinhauser KE, Christakis NA, Clipp EC: Preparing for the end of life: preferences of patients, families, physicians, and other care providers. $J$ Pain Symptom Manage 2001, 22:727-737.

56. Emanuel EJ, Emanuel LL: The promise of a good death. Lancet 1998, 351: SIII21-29.

57. Patrick DL, Engelberg RA, Nielsen E, McCown E: Measuring and improving the quality of dying and death. Ann Intern Med 2003, 139:717-726.

58. Vig EK, Davenport NA, Pearlman RA: Good deaths, bad deaths, and preferences for the end of life: a qualitative study on geriatric outpatients. J Am Geriatr Soc 2002, 50:1541-1548. 
59. Kehl KA: Moving toward peace: an analysis of the concept of a good death. Am J Hospice Pall Med 2006, 23:277-286.

60. Steinhauser KE, Clipp EC, McNelly M: In search of a good death: observations of patients, families, and providers. Ann Intern Med 2000, 132:825-832.

61. Gazelle G: A good death: not just an abtract concept. J Clin Oncol 2001, 19:917-918.

62. Kabengele Mpinga E, Chastonay P, Pellissier F: La "bonne mort": perceptions desprofessionnels de soins en Suisse romande. Recherche en Soins Infirmiers 2005, 80:4-11.

63. Steinhauser KE, Clipp EC, Tulsky JA: Evolution in measuring the quality of dying. J Palliat Med 2002, 5:407-414.

64. Patrick DL, Engelberg RA, Curtis JR: Evaluating the quality of dying and death. J Pain Symptom Manage 2001, 22:717-726.

\section{Pre-publication history}

The pre-publication history for this paper can be accessed here:http://www. biomedcentral.com/1472-684X/9/1/prepub

doi:10.1186/1472-684X-9-1

Cite this article as: Barazzetti et al.: What "best practice" could be in Palliative Care: an analysis of statements on practice and ethics expressed by the main Health Organizations. BMC Palliative Care 2010 9:1.

Publish with Biomed Central and every scientist can read your work free of charge

"BioMed Central will be the most significant development for disseminating the results of biomedical research in our lifetime. "

Sir Paul Nurse, Cancer Research UK

Your research papers will be:

- available free of charge to the entire biomedical community

- peer reviewed and published immediately upon acceptance

- cited in PubMed and archived on PubMed Central

- yours - you keep the copyright 